\title{
Competitiveness of the public transport and car owner behavior: interrelations and contradictions in the light of sustainable development of the metropolis
}

\author{
Irina Skorobogatykh, Zhanna Musatova*, Roman Sidorchuk, Natalia Ivashkova, and Petr \\ Nevostruev \\ Plekhanov Russian University of Economics, Stremyanny lane, 36, 115054 Moscow, Russia
}

\begin{abstract}
Consistent actions taken by car manufacturers to improve the quality of vehicles make them easier to use and reduce their negative impact on the environment significantly strengthen the competitiveness of personal transport. At the same time, high investments in the development of urban transport systems (especially large ones) create conditions for the mobility of all population groups, but do not significantly affect the competitiveness of public transport. At the same time, the high competitiveness of the public transport system is a sign of the successful implementation of the concept of sustainable development of the territory, making it more attractive for tourism and stimulating its development. The study of the limitations of the analysis of the competitiveness of public transport is conducted in this article along with an analysis of the factors that influence the choice of citizens in terms of mobility for their daily tasks. The article presents the results of an empirical study of relations between Moscow residents and public transport, changes in the intensity of use of personal cars in the period 2015-2020. During this period, the transport system has undergone significant positive changes, which have affected the perception of comfort and accessibility of public transport in Moscow.
\end{abstract}

\section{Introduction}

The competitiveness of public transport has been continuously challenged over the past 30 50 years, against the backdrop of a dramatic increase in the number of vehicles and their accessibility to individuals.

The competition for public transport and private cars is continuously fought for by both car manufacturers and city and regional governments. Private and public transport solves the same problem - ensuring transport accessibility of various objects (points of interest or attraction) for individuals (residents and visitors of cities). However, transport accessibility

\footnotetext{
* Corresponding author: Musatova.ZHB@rea.ru
} 
can be provided by different means with different levels of comfort, flexibility, freedom and preservation of an individual's personal space.

Year after year, car manufacturers improve the quality, design, comfort, technical equipment and information products of the cars they produce. The obvious prospect of entering the market for unmanned cars will further increase their competitiveness, as it will remove the restrictions imposed by the obligation to have rights to drive a car, and will also allow passengers to rest or do some business while driving. Solutions that simplify navigation, reduce fuel consumption and reduce exhaust gas levels also make it possible to claim that the use of private cars reduces the negative impact on the environment as well as the use of excess fuel resources.

Thus, all players in the automotive industry are continuously working on the issue of maintaining and increasing the competitiveness of private cars, and given the new technological and information opportunities and developments in the use of alternative fuels, it cannot be assumed that the competitiveness of private cars will decline in the near future.

A non-technological factor in maintaining the competitiveness of private motor vehicles is the ageing of the population, which is typical for European countries [1] as well as for Russia. As the population ages, the availability of public transport decreases, as transport is perceived to be less comfortable and reliable $[2,3]$ and mobility opportunities a priori decrease, which means that the quality of life decreases. Some groups of individuals with limited physical capacity also cannot be considered as potential passengers in public transport given the objective difficulty of involving them in the travel process. The main challenge for them is to limit the time they can spend on the road [4]. Families with two or more young children should also be included in this group. Their mobility needs are difficult to meet by public transport other than taxis and car sharing. Therefore, when considering the competitiveness of public transport, it makes sense to limit it in advance to groups of individuals who do not have significant physical limitations and who travel without young children.

In parallel, the public transport system is being actively developed in all major urban agglomerations, and substantial funds are being invested to maintain, modernize and develop fundamentally new solutions to the system. The state as a whole and the city authorities of any country are interested in creating an urban environment (an important element of which is the transport system) that will ensure economic growth, attractiveness for investment, prosperity of citizens and attraction of the best specialists as residents [5]. The main challenge for them is to limit the time they can spend on the road [4]. Families with two or more young children should also be included in this group. Their mobility needs are difficult to meet by public transport other than taxis and car sharing. Therefore, when considering the competitiveness of public transport, it makes sense to limit it in advance to groups of individuals who do not have significant physical limitations and who travel without young children.

The creation of a system of modern, accessible, environmentally friendly public transport is one of the most important elements in marketing the territory's infrastructure, which in turn reflects the success of the implementation of the concept of sustainable development based on the rational use of resources [6]. Individual countries and cities compete with each other for the right to attract financial and human resources. In order to improve the competitiveness of a particular city, it is necessary to systematically and consistently develop the urban environment, including ensuring that places of work, training, treatment, leisure and other facilities are accessible to all agglomeration residents.

For example, in Moscow, the amount of funds allocated for the development of the public transport system is growing significantly. The Transport Department is interested in obtaining operational data on how Moscow residents and tourists perceive the changes 
being made to improve public transport [7]. The data on budget development for the city program «Development of transport system» for the period 2017-2020 are given in Table 1.

Table 1. Budget of the Moscow city program "Development of Transport system"

\begin{tabular}{|c|l|l|l|l|l|l|}
\hline & 2017 & 2018 & 2019 & 2020 п & 2021 п & Total \\
\hline Total, million rubles & 644,1 & 642,7 & 738,3 & 733,6 & 718,4 & 3477,1 \\
\hline $\begin{array}{c}\text { Moscow City } \\
\text { Budget, million } \\
\text { rubles }\end{array}$ & 518,3 & 542,1 & 608,5 & 602,3 & 594,5 & 2865,7 \\
\hline $\begin{array}{c}\text { Federal budget funds, } \\
\text { million rubles }\end{array}$ & 14,7 & 11,8 & 16,6 & 17,1 & 27,8 & 88,1 \\
\hline $\begin{array}{c}\text { Funds of legal } \\
\text { entities and } \\
\text { individuals, mln. }\end{array}$ & 111,1 & 88,8 & 113,2 & 114,3 & 96,0 & 523,3 \\
\hline
\end{tabular}

Source: https://budget.mos.ru/

In the USA, total public transport costs increased from USD 22 billion to USD 58.5 billion between 1991 and 2012, with an average annual growth rate of 2.2\% (at comparable inflation-adjusted prices). Total transport volume in the same period rose from 2.5 billion miles to 4 billion miles, with an average annual growth rate of $2.3 \%$. [7]. Other countries, especially in the Asia-Pacific region, are also making unprecedented investments in public transport. However, there is not a proportionate increase in demand for transport services as the population grows. Such results cannot satisfy the interests of the state and society, because intensive (possibly excessive) exploitation of roads leads to their premature wear and tear, traffic congestion prevents the movement of special service vehicles, and the proximity to high-traffic volumes reduces the quality of life of people living there.

It is clear, however, that the competitiveness of public transport has certain limitations and must be taken into account when conducting research in this area. For many years, lack of a car has meant limited access to opportunities: work [8], study, leisure and communication. This perception persists with the rapid development of the public transport system, but the emergence of the tools of the sharing economy, in particular car sharing, is gradually, although slowly beginning to change this perception.

At the same time, the rationality of the use of cartridges varies greatly depending on the situation, and if it is necessary to make daily pendulum trips, cartridges will not be the best choice.

This study will focus on studying the behavior and attitudes to public transport of groups of individuals who use it for daily trips to places of work or study.

\section{Materials and methods}

In the first stage of the study, the method of content analysis of scientific publications (articles) on the competitiveness of public transport in large cities, as well as on the factors that influence the choice of citizens, was chosen. Scopus, WoS and ResearchGate electronic databases were used for the search, and queries were made using the key words "public transport "+"competitiveness", "travel mode "+"choice" used in the titles of publications, abstracts and the list of key words.

Next, a field study was used in the city of Moscow, the purpose of which was to identify the attitude of citizens to public transport and changes in the intensity of its use in the period 2015-2020. The survey was organized in an online format, a questionnaire was created on the Survey Monkey platform and the results were processed in Excel and SPSS packages. The survey was done in a sample of 2,275 respondents, and the sample was 
representative of the administrative districts of the city, including New Moscow. The demographic characteristics of the respondents in the sample correspond to those of the Moscow population.

\section{Results and Discussions}

When choosing the means of travel for regular trips (e.g. to work), people make long-term decisions (therefore, they are low elastic). Based on consumer choice theory, people choose their mode of transport based on an assessment of the characteristics of the various alternatives available to maximise personal usefulness. Since utility cannot be observed directly, a utility-based decision-making model estimates the probability with which a particular alternative will be chosen based on observation of people's behaviour.

Decisions are made on the basis of an assessment of internal (time, costs, work constraints) and external (a set of elements of the transport system and its availability). Decisions are based on a set of personal relationships, preferences, habits, culture, lifestyle and physical condition. Choices are often determined by an inflexible personal attitude, which is more important than costs. Researchers therefore conclude that it is possible to influence the choice of public transport without direct economic impact [9]. Above all, this is possible if the dogma of public transport changes and the quality of transport services increases at the same time [10].

It is difficult to determine how people define the perceived costs associated with each particular alternative and how they respond to changes in those costs. It is therefore difficult to identify an exhaustive list of all the parameters that determine a consumer's choice and collect data to measure these parameters. However, such attempts are being made by a number of researchers and, based on the results, it is possible to summarize the main list of factors that an individual takes into account when choosing a sustainable transport model. It is important to note that the cost of owning and operating a private car makes a significant contribution to the attractiveness of public transport. Traditionally, in the USA, the cost of travel by car is perceived as low, a similar situation has historically developed in the Russian market, but it is undergoing significant changes due to the gradual growth of these costs. In a number of European countries the situation is fundamentally different, for example, in the UK and France, the cost of owning and using a car is very high, so public transport is much more popular and its use is not associated with low-income consumers. Even more competitive is the use of public transport in Japan, Hong Kong and Singapore, where population density is highest, land prices are extremely high and the urban environment is complex.

Research carried out in different countries has helped to identify a number of factors that influence public transport preferences. For example, in Barcelona, the following factors were identified: waiting time, travel time, convenience of entry, frequency, cost [11]. Using data from Chicago [12], it was found that unreliable car traffic (unpredictability of travel time) has an impact on the probability of switching to public transport. A study conducted in Los Angeles [7] identified a number of significant factors that have the most significant impact on the likelihood of public transport preferences. These include the density of stops (number of stops per square mile), travel time, schedule reliability and frequency of traffic (permitted deviation from the schedule not exceeding 3 minutes). It has been estimated that if the travel time by private car is increased by more than 10 minutes compared to travel by public transport, it is $30 \%$ more likely to be selected.

Comparative studies are being carried out in developed countries on the behavior of household members who do not own private cars for various reasons: lack of opportunities to buy and operate them and the desire to be free of cars. Some researchers do not define such households as disposing of their cars, but rather of them [13]. 
It is important to divide individuals who do not purchase and operate personal cars into two groups based on the reasons for this decision: by choice or due to objective restrictions. A study [14] conducted in the State of California (USA) identified five segments of individuals who do not own private cars:

Segment 1: Environmentally friendly people are concerned about the negative impact of cars on the environment $(1.6 \%)$;

Segment 2. Those who do not need a car use public transport or micro-mobility means, and walk (18.3\%);

Segment 3: Those, who have financial restrictions on purchase, insurance and operation $(50.2 \%)$

Segment 4: Those people, who are not driving, because of health conditions and/or age $(10.3 \%)$

Segment 5: Cannot drive due to lack or inability to obtain rights or fear (19.6\%).

The first two segments made an involuntary decision to abandon the vehicle (their aggregate share is $19.9 \%$ ), the remaining three subgroups (with an aggregate share of $80.1 \%$ ) do not have a vehicle due to different restrictions.

Looking at the above subgroups on the other hand, one can see groups of public transport users. The first two subgroups use it according to their own conscious choice, while the remaining subgroups use it forcedly. Strictly speaking, the competitiveness of public transport can only be determined in relation to those individuals who have made a free choice in favor of public transport or private cars. It will also be relevant to clarify here that citizens who choose to use a private car do not always have an alternative in the form of public transport or micro-mobility. In this group, it would be appropriate to include people whose work involves a large number of trips during the day, transportation of goods, parents with small children, and people with disabilities who can objectively solve their daily tasks only by using a private car.

From the point of view of changes in the competitiveness of public transport in Moscow, it is advisable to assess the proportion of citizens who have started to use a private car less over the past 5 years. In order to identify the reasons for the decrease in the popularity of public transport, it is advisable to find out the share of those who have started using a private car more often. It is also important to investigate the reasons for the abovementioned changes.

Out of the sample of 2,275 people who could choose up to three options for the most frequent means of transport in Moscow, 49.7\% chose public transport, $26.8 \%$ chose a private car, $28.9 \%$ walk, $12.5 \%$ use a taxi, $3.3 \%$ use a cartwheel and $1.7 \%$ choose micromobility.

The distribution of answers to the question about changes in car use is shown in figure 1 .

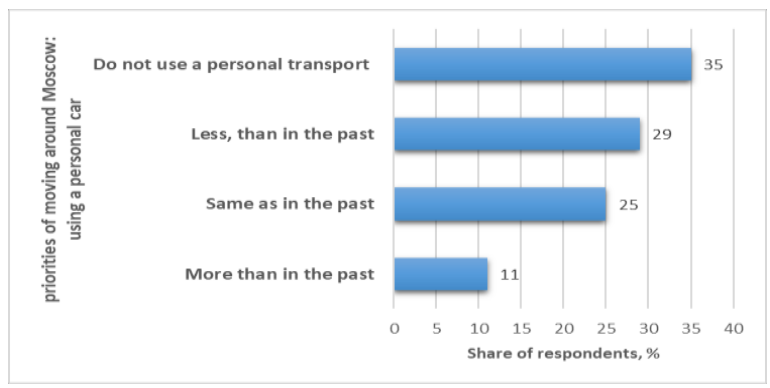

Fig. 1. Changes of the intensity of the use of private care for the last five years

The percentage of respondents who started using a car was $17.2 \%$, which is a noticeable sign that public transport is becoming more competitive. These results do not mean that 
respondents have completely abandoned the use of cars, but have started to drive less frequently or at shorter distances.

The reasons for the reduction in the use of private motor vehicles are mainly related to the quality of public transport and the cost of car ownership. The results are shown on figure 2 .

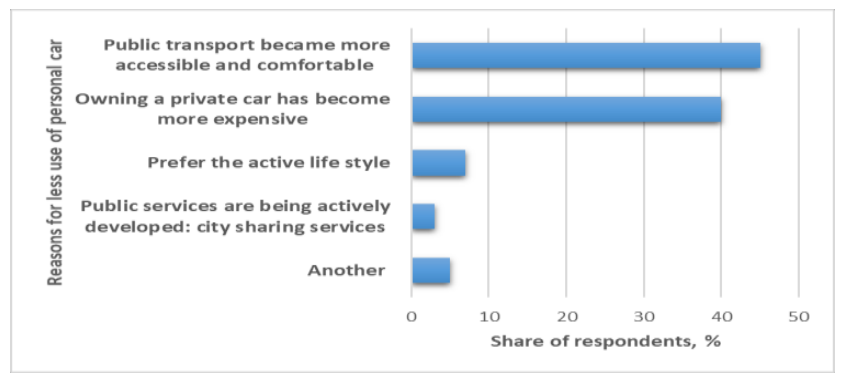

Fig. 2. Reasons for reducing the use of private cars

The main reason for this was the respondents' perception of public transport as more convenient $(45 \%)$, the second position was an increase in the cost of owning a private car (36.4\%), $7.9 \%$ said they prefer an active lifestyle, i.e. walk more, and $4.1 \%$ of respondents switched to car sharing.

It is also important to note that the horizon of the changes studied is measured in five years, which coincides with the start of active development of the karshoring service in Moscow, but the largest number of companies entering this market was recorded in 2017. There were also other variants of answers, in total, their share was $6.7 \%$. When analyzing the different variants, there was a distribution of these variants into three enlarged groups: traffic jams, expensive parking and fines for traffic violations, there was less need to move. Although the Other response rate was low, it is still possible to pay particular attention to the prevalence of responses due to high traffic congestion.

Let us turn to the reasons why residents have started to use their private car more over the last 5 years, see figure 3 . The share of such residents is insignificant $-6.2 \%$.

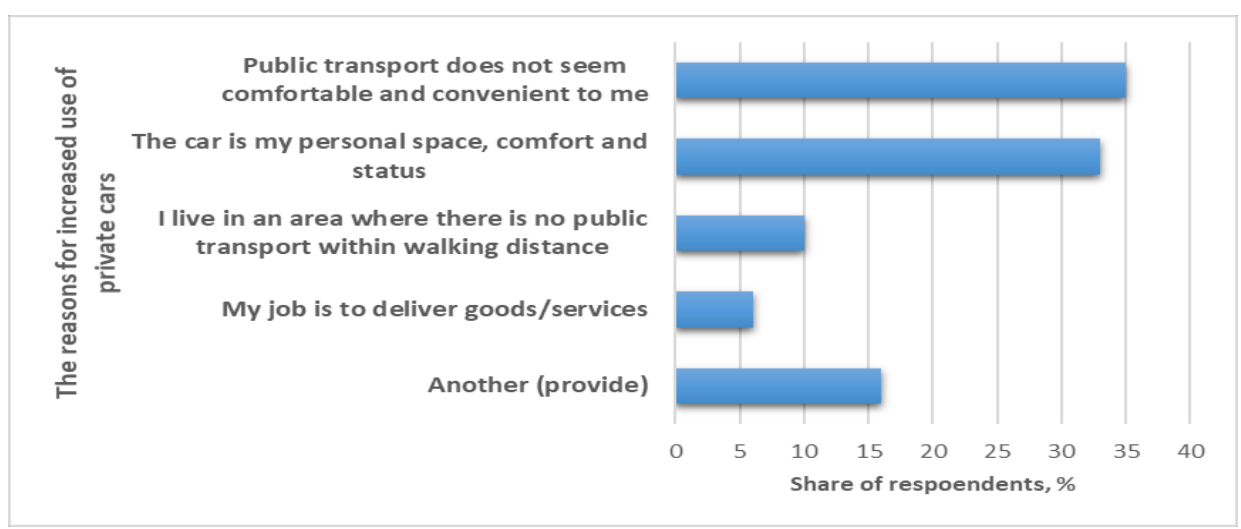

Fig. 3. Reasons for increased use of private car

The first reason for this is the perception of public transport as uncomfortable, mentioned by $35.2 \%$ of respondents, who increased the frequency of using a private car. The second most frequently mentioned reason is related to the perception of the car as a personal space, a feeling of comfort and a demonstration of status. $10.4 \%$ of respondents said that they do not have access to public transport stops at their place of residence, while $5.3 \%$ said that their work is related to the delivery of goods or services. The answer "other" 
was given by $16.1 \%$ of the respondents, so it is necessary to analyse these answers in more detail. The main reason is the shorter and more convenient road to work in a private car, as well as the work schedule, which makes it more convenient to travel by private transport (let's assume that the start of the working day is in the early morning), while the second most frequent reason is the opportunity to buy a car.

The difference in the percentage of respondents who have reduced and increased their use of a car is $11 \%$ ( $17.2 \%$ of those who use a car less $-6.2 \%$ use it more).

It is important to note that the main reason for the change in the use of private cars was the perception of public transport. Among those who have reduced the use of a car, $45 \%$ have done so due to their perception of it being more convenient, and among those who have increased the use of a private car, $35.2 \%$ have expressed the opposite opinion about the condition of public transport, which they believe has decreased comfort.

It can be assumed that individuals living in the same large city may perceive public transport differently, its comfort and reliability for different reasons. The first objective reason may be that respondents live in different districts and specific places in the city. The public transport network is not uniform, some places do not have convenient land transport routes or high-speed stations, and other areas have metro stations, but the line is heavily overloaded and is objectively uncomfortable to use. Another reason, in our opinion, is the subjective assessment of the condition of public transport and its comfort to passengers. It would be logical to assume that the difference in assessment stems from perceptions based on passenger values. Research into the values of individuals can give a new impetus to understanding perception patterns and attitudes towards public transport.

\section{Conclusions}

1. The study of public transport competitiveness is multidimensional and should be based on a large set of variables and factors that influence passenger behavior. An important factor in competitiveness is the actions taken by car manufacturers to reduce the environmental impact of cars, which negates the strength of the arguments on the environmental disadvantage of cities with large numbers of cars. At the same time, high investments in the development of public transport (a special intercity transport) do not yield a high return on passenger turnover growth.

2. The question of the competitiveness of public transport can only be relevantly considered with regard to those groups of individuals who can objectively and without restriction solve their daily tasks using public transport. These groups cannot include people with disabilities who have to transport goods to different places during the day, people travelling with young children, etc.

3. The choice between using private and public transport is determined by many factors, most of which can be considered subjective, reflecting an individual's personal relationship to understanding personal comfort.

4. In developed countries (including the United States) there is a tendency to avoid using private cars as a method of getting rid of some of the everyday hassle. However, studies show that less than $20 \%$ of city dwellers do not use private transport for reasons of conscious choice or environmental beliefs. The rest make choices in favor of public transport under the influence of restrictions.

5. Studies conducted as part of a sample survey in Moscow show that over the last 5 years, $17.2 \%$ of citizens have started to use a private car less and $6.2 \%$ have started to use private transport more. The main reason for the change in the intensity of private car use was a change in perception of the public transport system. This result looks paradoxical and 
opens new areas for research into the significant difference in perception of the public transport system.

6. An additional area of research should be the phenomenon of micro-mobility of citizens using bicycles, scooters, gyro scooters and mono-wheels. Given the high speed that individual vehicles with electric drive can develop, these micro-mobility vehicles are beginning to be a real competition for public transport, especially land transport, which is the most vulnerable due to low speed.

\section{References}

1. M. Thériault, F. Des Rosiers. Proceedings of the 7th AGILE conference on geographic information science (2004)

2. A. Walker. Understanding Quality of Life in Old Age (2005)

3. D. Banister, A. Bowling, Transport Policy, 11 (2004)

4. P.R. Oxley, M. J. Richards, Transport Policy, 2 (1995)

5. R. Gemmiti. Urban competitiveness, culture and tourism. Critical aspects in Rome planning experience. Universita did Roma La Sapienza (2012)

6. I. Skorobogatykh, D. Malova, Z. Musatova, E. Agalarova. Am J Appl Sci, 13 (2016)

7. R. Sidorchuk \& I.Skorobogatykh. Med J Soc Sci 6 (2015)

8. S. Chakrabarti, Transport Policy, 54 (2017)

9. J. Grengs, J. Transp. Geogr., 18 (2010)

10. V. Johansson, T. Heldt, P., Johansson. Trans. Res. Part A: Policy Pract., 40 (2006)

11. C.M. Collins, S.M. Chambers. Environ. Bahav., 37 (2005)

12. J. Asensio. Urban Stud., 39 (2002)

13. M.N. Sweet, M. Chen. Transportation, 38 (2011)

14. B. Clark, K.Chatterjee, S. M. Melia. Transportation, 43 (2016)

15. A.E. Brown. Transport policy, 60 (2017) 